\title{
LO REPRESENTABLE. PUJAS PÚBLICAS, ACTORES, ARENA PARLAMENTARIA Y LEYES CANDENTES EN LA POLÍTICA ARGENTINA
}

de Mariana Berdondini, Rosario, Prohistoria Ediciones, 2016, 320 pp.

LUCÍA VINUESA

Consejo Nacional de Investigaciones Científicas y tecnológicas / Instituto de Investigaciones de la Facultad de Ciencias Políticas y Relaciones Internacionales.

A partir del análisis detallado de dos leyes candentes de la historia reciente argentina, la autora de Lo representable, nos introduce en la complejidad de la lógica de la política y de lo político, así como del sistema representativo democrático una vez que los marcos interpretativos y de sentido de la vida en común se alteran producto del impacto que tuvo la crisis política, económica, social y cultural del 2001-2002. La virtud del libro consiste en hacer confluir en el análisis, la variable histórica de mediano y corto plazo, junto al análisis político específicamente coyuntural y a los marcos epistémicos que ayudan a comprender el modo en que algunas voces logran hacerse oír y devienen representables.

Las unidades de observación son dos leyes sancionadas en el período 2003-2011, a saber: Ley de Servicios de Comunicación Audiovisual (LSCA) no 26.522 de 2009 y
Ley de Matrimonio Civil (más conocida como Ley de Matrimonio Igualitario) no 26.618 de 2010. Estas disposiciones tienen la particularidad de interpelar lo instituido, por lo cual resultan eminentemente litigiosas. Ambas dan cuenta de la aparición de los representables, aquellos -actores o intereses- que se constituyen en el acto mismo de la presentación y representación, más allá de no encontrarse en el sistema político formalmente e ilustran una diversidad de voces del espacio público no siempre audibles.

Luego de largas luchas por hacerse presentes y tener voz, estos representables logran interpelar a las instituciones y a los actores formales de la representación clásica, ponen en cuestión la idea misma de ciudadanía y dan cuenta de la complejidad de la democracia representativa contemporánea. En base a dicho diagnóstico, 
Berdondini hace confluir dimensiones electorales y no electorales, con lógicas verticales y horizontales, para pensar la relación representantes y representados, junto a la participación y a la movilización como elementos constitutivos del modo de hacer presente y de la política actual.

La hipótesis rectora del libro parte de problematizar la forma representativa clásica, considera, en cambio, que la idea de representación democrática se amplía con formas plurales no electorales. Esto implica, entre otras cuestiones, que la representación democrática lejos de estar situada o resuelta en un lugar, es una maraña compleja de relaciones, mediaciones e interacciones múltiples, conflictivas y plurales que tejen instituciones estatales, actores políticos y sociales. Su abordaje requiere tener en cuenta las arenas formales y no formales, circuitos diversos y escalas internacionales en las que la disputa por «lo común» deja traslucir qué sentidos de la democracia y de sujeto político se ponen en juego. Al mismo tiempo, complejiza los clásicos estudios legislativos con la pretensión de llenar lo que aparece como un vacío del espectro de actores y procesos extraparlamentarios que inciden en la actividad legislativa.

Cada uno de estos casos se abordan en el cuerpo del libro, especialmente en los capítulos II, III, IV y V. En principio nos encontramos con un análisis que antecede al arribo y a la discusión parlamenta- ria, que resulta pertinente para comprender las aristas litigiosas, los modos, los tiempos e implicancias en cuestión. A continuación, se desarrolla el tratamiento que recibió cada una de las leyes al interior del Parlamento, para cuyo análisis resultan ineludibles los actores sociales, empresariales e institucionales, que actuaban e intervenían política y socialmente por fuera del recinto. La autora ofrece una historización de los procesos por y en el cual «aparecen» los temas, los actores y las prácticas que transitan diversas escalas para hacerse visibles y manifiestos. A partir de esta perspectiva, el proceso democrático no sólo es la base de estas construcciones sino que también es el puntapié para cuestionarla, al denunciar las clausuras y exclusiones del acceso a derechos, $y$, en definitiva, al poner en escena la noción misma de ciudadanía.

En el primer capítulo del libro se presentan las herramientas teóricas para pensar la complejidad de la democracia en su trama representativa contemporánea, asociada a las transformaciones en el espacio público y el lugar del Parlamento. La democracia «de lo público», «aclamativa» o «la contrademocracia», refleja las contradicciones propias de la representación y la democracia, al tiempo que resulta del proceso de democratización del último cuarto del siglo XX. Con un bagaje bibliográfico extenso, Berdondini transita por la tradición clásica de la teoría polí- 
tica, entre quienes podemos mencionar a Manin, Rosanvallon, Pitkin, Michels, pasando por Habermas, Lefort, incluso Rancière para pensar estos públicos que interpelan lo común estatuido, así como referencias ineludibles de la Ciencia Política, O’Donnell, Schmitter, Lechner, Whitehead, Oszlak, Peruzzotti, Calvo y Portantiero, entre otros.

La autora recala en las lógicas contrapuestas que condensa la «democracia representativa», es decir, una lógica vertical, basada en la relación representantes y representados, y otra horizontal, que se pone de manifiesto en la participación de los actores sociales. Entre ambas vemos confluir actores e intereses disímiles, que, a pesar de los cambios en los modos de la política, siguen interpelando al Parlamento, institución central (y conflictiva) de la encrucijada. El sentido de la representación que se puso en juego implicó hacer presente la diversidad, pluralidad de intereses y puntos de vista, al lado de la deliberación e intercambio de ideas y argumentos figurados en el Parlamento, que en la democracia contemporánea atraviesa circuitos múltiples para manifestarse pública, política e institucionalmente.

Por otro lado, Berdondini nos recuerda que los límites entre lo privado y lo público se alteran, así como lo estatal y no estatal, lo cual impacta en el espacio público democrático. Las acciones que se llevan a cabo en múltiples escalas interpelan lo estatuido y al Estado, hacen de aquello que era privado y personal algo político, rompen reglas institucionales, cuestionan el orden, trastocan «lo común» y es así como habilitan una ampliación de las condiciones de ciudadanía, de derechos y de la representación del pueblo.

En el segundo capítulo, la autora emprende una exquisita historización de las luchas por los cambios en las reglas de juego del sistema comunicacional, recuperando sus propias palabras, se abogó «por la comunicación como derecho humano universal, bien social y, por lo tanto, servicio público, esencial para la democratización y la ciudadanía» (p. 83). La disputa en torno a la comunicación, que anticipó la LSCA, problematizó el rol de los medios de comunicación masiva como actores eminentemente políticos. La autora describe minuciosamente los hitos normativos, que se articulan con las prácticas del activismo en escalas internacionales y nacionales, y habilitan la concreción legislativa. Ésta revierte las políticas de comunicación que hasta ese momento se caracterizaron por restringirse a acuerdos privilegiados entre los gobiernos de turno -ya sean civiles o militares- y las empresas privadas.

Un aspecto reiterativo al destacar el movimiento por la democratización comunicacional, consiste en la puesta en escena de los efectos conglomerales y concentra- 
dos de la propiedad privada y la libre empresa y su incidencia en la libre expresión. Berdondini hace hincapié en dichos elementos en la medida en que no sólo resultan excluyentes de otros actores y modos, sino que, al mercantilizar dicha función y trabajar exclusivamente con la lógica del mercado, privan del acceso a la ciudadanía de dar y recibir comunicaciones e informaciones plurales y diversas. A su vez, la autora aporta a la discusión acerca del sentido y la extensión del mentado derecho a la libertad de expresión, nuevamente teniendo en cuenta la misma como un derecho muchas veces privatizado en manos de grupos económicos monopólicos.

En el tercer capítulo, Berdondini expone meticulosamente los acontecimientos sociales, políticos y normativos que transcurrieron en torno al arribo a la agenda pública y política del proyecto de ley en el que culmina la LSCA. Con especial énfasis en el proceso legislativo, la autora describe las posiciones de los actores políticos, al tiempo que los intercambios que estos mantuvieron con actores sociales y empresariales, para un lado y otro de la balanza. Ilustra el modo en que lo representable cuestiona lo estatuido, puja por hacerse presente en la agenda pública y política, y logra el tratamiento de la ley junto a un proceso de discusión pública política inusitado respecto al rol de los medios de comunicación, su carácter de actores políticos, los rasgos materiales y simbólicos, la relación con la concentración, la libertad de expresión y de prensa. Al mismo tiempo, el debate entablado deshace la neutralidad valorativa que acompañó a las demandas empresariales por la libertad de expresión.

En el capítulo IV, bajo la consigna feminista «lo personal es político», la autora problematiza el modo en que la politización de la sexualidad denota los esfuerzos intelectuales y prácticos por mostrar el carácter social, históricamente construido, contingente y político del género, en oposición a su definición como natural. En este camino, la Ley de Matrimonio Igualitario, lejos de constituir una conquista política aislada, forma parte de un conjunto de luchas que politizaron las relaciones sociales consideradas privadas o naturales, que obligan a revisar los límites instituidos entre lo privado y lo público, y que ponen en cuestión la noción misma de ciudadanía y de derechos. Entre estas luchas, Berdondini destaca el recorrido emprendido por los movimientos feministas tanto a escala nacional como internacional desde la década de 1960.

A lo largo de dicho capítulo la autora traza una línea entre las demandas de las feministas por el estatuto del género, la politización de lo íntimo y personal, la decisión sobre el cuerpo y las minorías sexuales, al tiempo que vislumbra en la Ley de divorcio vincular ( $\mathrm{n}^{\circ}$ 23.515), de 1987, un antecedente directo de la de 
Matrimonio Igualitario. En el capítulo siguiente, luego de describir las leyes de la década de 1990 que dan cuenta del modo en que ingresan en la agenda los derechos sexuales y de salud reproductiva, especialmente a causa de la normativa acerca del VIH/Sida, vemos que la discusión parlamentaria sobre derechos conyugales para las personas del mismo sexo, se cuestiona políticamente y se rompe por primera vez con la heteronomía, o bien, el principio en función del cual las relaciones afecticas y familiares reconocidas por el Estado se basan en la unión reproductiva de una mujer y un varón.

Tras una serie de marchas, campañas y actos desafiantes, el proyecto de ley que exige el matrimonio igualitario entre personas de distinto y de igual sexo llega al Congreso y pone de manifiesto un desfile de posturas conservadoras que oponen resistencia al reconocimiento de derechos. Al mismo tiempo que la autora expone las discusiones al interior del recinto parlamentario, recupera las voces que lograron tornarse audibles por fuera de dicho marco institucional. Ya sea de parte de quienes se horrorizaron frente a la descomposición de la norma hetero- sexual obligatoria dominante, o de quienes recordaron su carácter de ciudadanos con derechos civiles y disputaron la importancia de los nombres en el reconocimiento legislativo.

A modo de reflexión final, es posible decir que las leyes de la historia política argentina reciente retomadas en el libro, a pesar de su especificidad ineludible -abordada por la autora con un nivel exquisito de precisión y profundidad descriptiva-, dejan traslucir los juegos entre la lógica de la política y de lo político, las voces de los incontados, de quienes logran hacerse presentes interpelando lo estatuido, tornando efectivamente representada una cuestión o un actor representable. En esta trama, las instituciones y la legalidad lejos de resultar caducas o vacuas, continúan ocupando un lugar central para nuestra democracia y la vida en común, especialmente para materializar las conquistas por la igualdad y el reconocimiento de derechos. Sin dudas, tal como se afirma en la obra de Berdondini, la irrupción de lo representable es contingente y a veces efímera, pero sólo el «procesamiento público e institucional posibilita trastocar los marcos de sentido existentes» (p. 263). 